\title{
A Comparison of Leak Compensation in Acute Care Ventilators During Noninvasive and Invasive Ventilation: A Lung Model Study
}

\author{
Jun Oto MD PhD, Christopher T Chenelle, Andrew D Marchese, \\ and Robert M Kacmarek PhD RRT FAARC
}

\begin{abstract}
BACKGROUND: Although leak compensation has been widely introduced to acute care ventilators to improve patient-ventilator synchronization in the presence of system leaks, there are no data on these ventilators' ability to prevent triggering and cycling asynchrony. The goal of this study was to evaluate the ability of leak compensation in acute care ventilators during invasive and noninvasive ventilation (NIV). METHODS: Using a lung simulator, the impact of system leaks was compared on 7 ICU ventilators and 1 dedicated NIV ventilator during triggering and cycling at 2 respiratory mechanics (COPD and ARDS models) settings, various modes of ventilation (NIV mode [pressure support ventilation], and invasive mode [pressure support and continuous mandatory ventilation]), and 2 PEEP levels (5 and $10 \mathrm{~cm} \mathrm{H}_{2} \mathrm{O}$ ). Leak levels used were up to 35-36 L/min in NIV mode and 26-27 L/min in invasive mode. RESULTS: Although all of the ventilators were able to synchronize with the simulator at baseline, only 4 of the 8 ventilators synchronized to all leaks in NIV mode, and 2 of the 8 ventilators in invasive mode. The number of breaths to synchronization was higher during increasing than during decreasing leak. In the COPD model, miss-triggering occurred more frequently and required a longer time to stabilize tidal volume than in the ARDS model. The PB840 required fewer breaths to synchronize in both invasive and noninvasive modes, compared with the other ventilators $(P<.001)$. CONCLUSIONS: Leak compensation in invasive and noninvasive modes has wide variations between ventilators. The PB840 and the V60 were the only ventilators to acclimate to all leaks, but there were differences in performance between these 2 ventilators. It is not clear if these differences have clinical importance. Key words: leak compensation; mechanical ventilation; acute care ventilator. [Respir Care 2013;58(12):2027-2037. (C) 2013 Daedalus Enterprises]
\end{abstract}

\section{Introduction}

During mechanical ventilation, system leak is a major cause of patient-ventilator asynchrony. ${ }^{1}$ Leaks may be due to the endotracheal tube cuff, ventilator circuit, or chest drain during invasive ventilation. The incidence of endotracheal tube cuff leaks has been reported at ranges from $11 \%$ to $24 \% .^{2,3}$ With noninvasive ventilation (NIV), leaks

The authors are affiliated with Respiratory Care Services, Massachusetts General Hospital, Boston, Massachusetts.

Supplementary material related to this paper is available at http:// www.rcjournal.com.

Dr Kacmarek presented a version of this paper at the AARC Congress 2012, held November 10-13, 2012, in New Orleans, Louisiana. around the face or nasal mask are a common cause of system leak. ${ }^{1}$ Patient-ventilator asynchronies have been reported to occur with a high incidence during both invasive $^{4,5}$ and NIV.6,7 Thille et al reported that $24 \%$ of patients showed patient-ventilator asynchrony in $>10 \%$ of

Deputy Editor Richard Branson guided this paper through peer review.

This research was partly supported by Covidien. Dr Kacmarek has disclosed relationships with Maquet and Covidien. The other authors have disclosed no other conflicts of interest.

Correspondence: Robert M Kacmarek PhD RRT FAARC, Respiratory Care Services, Massachusetts General Hospital, 55 Fruit Street, Boston MA 02114. E-mail: rkacmarek@partners.org.

DOI: $10.4187 /$ respcare. 02466 
their total ventilatory rate during invasive ventilation. ${ }^{5}$ Vignaux et al demonstrated that auto-triggering was present in $13 \%$ of patients, and delayed cycling in $23 \%$ of patients during NIV. ${ }^{6}$ Patient-ventilator asynchrony can significantly increase the work of breathing, ${ }^{8,9}$ and a high incidence of patient-ventilator asynchrony is associated with a longer duration of mechanical ventilation. ${ }^{4,5}$

\section{See the Related Editorial on Page 2194}

Although ICU ventilators were initially built to function without leaks, leak compensation has been added to ICU ventilators to improve patient-ventilator synchronization in the presence of system leaks. Ideally, leak compensation should automatically adjust during triggering and cycling to ensure that the ventilator rapidly responds to changes in leak without affecting patient-ventilator synchrony and maintains pressurization capacities. Ferreira et al evaluated the ability of 9 critical-care ventilators to function in the presence of leaks. ${ }^{10}$ The BiPAP Vision and the Servo-i were the only ventilators able to adapt to the leaks. Carteaux et al reported that dedicated NIV ventilators promoted better patient-ventilator synchronization than critical care and transport ventilators, even when the NIV mode was used. ${ }^{11}$

Technological improvements by ventilator companies are introduced rapidly. Currently there is no assessment of the performance of many ICU ventilators or the recent upgrades of ICU ventilators on their ability to prevent triggering and cycling asynchrony in both NIV and invasive ventilation. The aim of our study was to evaluate the ability of current acute care ventilators to prevent triggering and cycling asynchrony caused by increasing and decreasing leaks during both NIV and invasive ventilation.

\section{Methods}

Seven ICU ventilators (Maquet Servo-i, Covidien PB840, Hamilton C3, Hamilton G5, GE Healthcare CareStation, Dräger V500, and CareFusion Avea) and one dedicated NIV ventilator (Respironics V60) (Table 1) were compared using a lung simulator (ASL5000, IngMar Medical, Pittsburgh, Pennsylvania) ${ }^{12}$ during increasing and decreasing system leaks.

\section{Lung Model and Manikin Setup}

The simulator was adjusted to simulate COPD and ARDS. In the COPD model, compliance was $60 \mathrm{~mL} /$ $\mathrm{cm} \mathrm{H}_{2} \mathrm{O}$, inspiratory resistance was $10 \mathrm{~cm} \mathrm{H}_{2} \mathrm{O} / \mathrm{L} / \mathrm{s}$, and expiratory resistance was $20 \mathrm{~cm} \mathrm{H}_{2} \mathrm{O} / \mathrm{L} / \mathrm{s}$. In the ARDS model, compliance was $20 \mathrm{~mL} / \mathrm{cm} \mathrm{H}_{2} \mathrm{O}$ and inspiratory and expiratory resistance were $5 \mathrm{~cm} \mathrm{H}_{2} \mathrm{O} / \mathrm{L} / \mathrm{s}$. The inspira-

\section{QUICK LOOK}

\section{Current knowledge}

During noninvasive ventilation leaks can cause autotriggering and inappropriate cycling of breaths. Different ventilators demonstrate significant differences in their ability to compensate for leaks and achieve patient-synchrony.

\section{What this paper contributes to our knowledge}

Leak compensation in invasive and noninvasive modes demonstrated wide variations between ventilators, with regard to the ventilators' ability to reestablish synchrony. Ventilator performance, ventilator settings, and leak size all play an important role in determining appropriate triggering and cycling of breaths.

tory time of the simulator was $0.92 \mathrm{~s}$, the maximum inspiratory pressure drop was $-5 \mathrm{~cm} \mathrm{H}_{2} \mathrm{O}$, the pressure drop generated $0.1 \mathrm{~s}$ after the onset of an occluded inspiratory effort was $-3.6 \mathrm{~cm} \mathrm{H}_{2} \mathrm{O}$, and the breathing frequency was 15 breaths/min. For the profile of the negative pressure created by the respiratory muscles, $5 \%$ of the respiratory cycle time was active inspiration, $3 \%$ was an endinspiratory hold, and $15 \%$ was for return of pressure to baseline. The ASL5000 incorporates a series of 3 usercontrolled leaks with a simulator bypass and leak valve module. $^{12}$

In the NIV mode, a manikin head was used to simulate the patient-mask interface (see the supplementary materials at http://www.rcjournal.com). An oronasal face mask (PerformaTrack SE, Respironics, Murrysville, Pennsylvania) was affixed to the head of the manikin with standard straps. A baseline leak of 3-4 L/min (baseline leak: B) at a mean airway pressure of $7.5 \mathrm{~cm} \mathrm{H}_{2} \mathrm{O}$ was established. The simulator bypass and leak valve module was set to leaks of 9-10 L/min (leak level 1: L1), 26-27 L/min (L2), and $35-36 \mathrm{~L} / \mathrm{min}$ (L3) at a mean airway pressure of $7.5 \mathrm{~cm} \mathrm{H}_{2} \mathrm{O}$. We chose these levels to represent the range of leak flows that are likely to be experienced clinically. ${ }^{13}$ All combinations of increasing $(n=6)$ and decreasing $(n=6)$ leaks were evaluated.

During invasive ventilation, the ventilators were affixed to the lung model with an $8 \mathrm{~mm}$ internal diameter endotracheal tube (see the supplementary materials at http:// www.rcjournal.com). The simulator bypass and leak valve module was set to leaks of 3-4 L/min (L1), 9-10 L/min (L2), and 26-27 L/min (L3) at a mean airway pressure of $7.5 \mathrm{~cm} \mathrm{H}_{2} \mathrm{O}$. All combinations of increasing $(n=6)$ and decreasing $(n=6)$ leaks were evaluated. 


\section{A Comparison of Leak Compensation in Acute Care Ventilators}

Table 1. Ventilator Specifications

\begin{tabular}{|c|c|c|c|c|}
\hline Ventilator & Software & Leak Compensation & Inspiratory Trigger Range & $\begin{array}{c}\text { Expiratory } \\
\text { Cycle Range } \\
\% \text { of inspiratory flow }\end{array}$ \\
\hline Servo-i & V5.00.00 & $\begin{array}{l}\text { Noninvasive ventilation mode: } 50 \mathrm{~L} / \mathrm{min} \\
\text { Invasive ventilation mode: none }\end{array}$ & $\begin{array}{l}0-100 \% \\
-20 \text { to } 0 \mathrm{~cm} \mathrm{H}_{2} \mathrm{O}\end{array}$ & $1-40$ \\
\hline PB840 & 4-070212-85-AG & $\begin{array}{l}\text { Noninvasive ventilation mode: } 65 \mathrm{~L} / \mathrm{min} \\
\text { Invasive ventilation mode: } 65 \mathrm{~L} / \mathrm{min}\end{array}$ & $0.2-20 \mathrm{~L} / \mathrm{min}$ & $1-80$ \\
\hline $\mathrm{C} 3$ & 1.0 .0 & No information available & $0.5-15 \mathrm{~L} / \mathrm{min}$ & $5-70$ \\
\hline G5 & $2.1 \mathrm{X}$ & No information & $0.5-15 \mathrm{~L} / \mathrm{min}$ & $5-70$ \\
\hline V500 & 2.23 & $180 \mathrm{~L} / \mathrm{min}$ & $0.2-15 \mathrm{~L} / \mathrm{min}$ & $5-70$ \\
\hline CareStation & 5.0 & No information available & $\begin{array}{l}1-9 \mathrm{~L} / \mathrm{min} \\
-10 \text { to } 0 \mathrm{~cm} \mathrm{H}_{2} \mathrm{O}\end{array}$ & $5-50$ \\
\hline Avea & 4.4 & No information available & $0.1-20 \mathrm{~L} / \mathrm{min}$ & $5-45$ \\
\hline V60 & PN 1076723 Auto-Trak+ & $60 \mathrm{~L} / \mathrm{min}$ & Auto-Trak & Auto-Trak \\
\hline
\end{tabular}

\section{Ventilator Setup}

During the NIV assessment, all of the ventilators were set in NIV mode as follows: pressure support ventilation (PSV); inspiratory pressure $12 \mathrm{~cm} \mathrm{H}_{2} \mathrm{O}$; PEEP 5 or $10 \mathrm{~cm} \mathrm{H}_{2} \mathrm{O}$; breathing frequency 10 breaths/min; and leak compensation activated if available. Trigger sensitivity was set to $3 \mathrm{~L} / \mathrm{min}$ if available. Inspiratory rise time, when adjustable, was set to the most rapid setting while avoiding overshooting of the set peak pressure. In the COPD model, the termination criteria, when adjustable, was set to ensure that the lung model's end of inspiration and the ventilator's end of inspiration did not differ by more than $\pm 5 \%$ at baseline leak. In the ARDS model the termination criteria were set at $25 \%$ of the peak flow. The maximum duration of inspiration was set to $1.5 \mathrm{~s}$.

During invasive ventilation, all the ventilators were set in PSV and continuous mandatory ventilation (CMV): pressure level $12 \mathrm{~cm} \mathrm{H}_{2} \mathrm{O}$; PEEP 5 or $10 \mathrm{~cm} \mathrm{H}_{2} \mathrm{O}$; breathing frequency 10 breaths/min; and leak compensation activated if available. Trigger sensitivity and cycling criteria were set the same as during NIV. In CMV mode the inspiratory time was set at $0.90 \mathrm{~s}$, approximately equal to the inspiratory time of the lung model (0.92 s).

\section{Variables and Evaluation}

For the evaluation of synchronization we recorded the number of breaths to synchronization after leak change (breaths to synchronization). The following variables were also recorded: auto-triggering, the number of cycles not triggered after a change in leak until synchronization; misstriggering, the number of efforts not recognized by the ventilator prior to synchronization; time to settle, the number of breaths from the moment leak was increased or decreased until the tidal volume was within 2 standard deviations of the mean tidal volume for each leak level. In addition, the following variables were evaluated: time to baseline pressure, the time from the beginning of an inspiratory effort to the return of airway pressure to baseline during triggering; triggering pressure, the airway pressure change needed to trigger; delivered tidal volume, and cycling delay time, time from the end of inspiratory effort to the moment the ventilator cycled to expiration. Each specific evaluation scenario was repeated 3 times.

\section{Data Collection and Analysis}

After each change in leak level we waited up to $1 \mathrm{~min}$ for the ventilator to synchronize with the simulator. If synchronization was not achieved, the ventilator was considered unable to compensate at that specific leak setting, and data were not collected. If synchronization was achieved within $1 \mathrm{~min}$, a total of 2 min of data after each change in leak level was collected and analyzed. Offline analysis of each breath was performed by the lung model's software (Labview, National Instruments, Austin, Texas). A $P<.05$ was considered significant. Data are presented as mean $\pm \mathrm{SD}$ or median (IQR), depending on the parametric or non-parametric nature of the data distribution. Regarding the time to baseline pressure, triggering pressure, delayed cycling time, and delivered tidal volume, we report only differences that were both statistically significant $(P<.05)$ and clinically important $(>10 \%)$.

\section{Results}

\section{Synchronization}

In NIV mode the Servo-i, PB840, C3, and V60 synchronized to all increasing and decreasing leaks in both the COPD model and the ARDS model (Tables 2 and 3). In invasive mode only the PB840 and the V60 synchronized 


\section{A Comparison of Leak Compensation in Acute Care Ventilators}

Table 2. Synchronization Capability Under Leak Scenarios During Noninvasive Ventilation Modes

\begin{tabular}{|c|c|c|c|c|c|c|c|c|c|c|c|c|}
\hline & \multicolumn{3}{|c|}{ Breaths to Synchronization } & \multicolumn{3}{|c|}{ Auto-triggering } & \multicolumn{3}{|c|}{ Miss-triggering } & \multicolumn{3}{|c|}{ Time to Settle } \\
\hline & $\mathrm{L} 1$ & L2 & L3 & $\mathrm{L} 1$ & L2 & L3 & L1 & L2 & L3 & $\mathrm{L} 1$ & $\mathrm{~L} 2$ & L3 \\
\hline Servo-i & 1.5 & 3.7 & 4 & 0.5 & 4.7 & 5.8 & 0 & 1.8 & 2.2 & 1.5 & 4 & 4 \\
\hline PB840 & 0.2 & 1 & 1.2 & 0 & 1 & 1 & 0.2 & 0 & 0.7 & 1 & 1 & 1 \\
\hline $\mathrm{C} 3$ & 1.8 & 1.8 & 2.3 & 0 & 2.8 & 3.2 & 1.3 & 1.8 & 2.3 & 3 & 2 & 2.5 \\
\hline G5* & 3.2 & $3.2 *$ & $3.2 *$ & 0 & $5.7 *$ & $6.5^{*}$ & 4 & $3.2 *$ & $3.2^{*}$ & 4 & $3.2 *$ & $3.2 *$ \\
\hline CareStation & 3.2 & NA & NA & 1.8 & NA & NA & 3.2 & NA & NA & 7.3 & NA & NA \\
\hline V500 & 3 & NA & NA & 0 & NA & NA & 3 & NA & NA & 5 & NA & NA \\
\hline Avea & NA & NA & NA & NA & NA & NA & NA & NA & NA & NA & NA & NA \\
\hline V60 & 0.2 & 2.5 & 4.2 & 0 & 1.8 & 2 & 0.2 & 1.7 & 3.7 & 1.2 & 2.7 & 4.7 \\
\hline $\begin{array}{l}\text { Values are medi } \\
\text { L1 include the v } \\
\text { L2 include the } \\
\text { L3 include the } \\
\text { * The G5 row s } \\
\text { NA = not appli }\end{array}$ & $\begin{array}{l}\mathrm{e} \text { L1, L2 } \\
\mathrm{f} \rightarrow \mathrm{L} 1 \\
\mathrm{f} \mathrm{B} \rightarrow \mathrm{L} 2 \\
\mathrm{f} \rightarrow \mathrm{L} \rightarrow \\
\text { aly the } \mathrm{F} \\
\text { id not } \mathrm{s}\end{array}$ & $\begin{array}{l}\mathrm{L} 3 \text { codes } \\
\mathrm{L} 1 \text {, and } \mathrm{I} \\
\mathrm{L} 2 \text {, and } \mathrm{I} \\
\mathrm{L} 3 \text {, and } \mathrm{I} \\
\mathrm{cm} \mathrm{H}_{2} \mathrm{O} \\
\text { iize }\end{array}$ & $\begin{array}{l}\text { plained ir } \\
1 . \\
2 . \\
\text { s. } \\
\text { in the L }\end{array}$ & ext. & cause & id not & ize at & f $10 \mathrm{~cm}$ & the L2 & 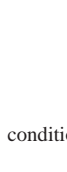 & & \\
\hline
\end{tabular}

Table 3. Synchronization Capability Under Leak Scenarios During Invasive Ventilation Modes

\begin{tabular}{|c|c|c|c|c|c|c|c|c|c|c|c|c|}
\hline & \multicolumn{3}{|c|}{$\begin{array}{l}\text { Breaths to } \\
\text { Synchronization }\end{array}$} & \multicolumn{3}{|c|}{ Auto-triggering } & \multicolumn{3}{|c|}{ Miss-triggering } & \multicolumn{3}{|c|}{ Time to Settle } \\
\hline & L1 & L2 & L3 & L1 & L2 & L3 & L1 & L2 & L3 & L1 & L2 & L3 \\
\hline \multicolumn{13}{|l|}{ PSV mode } \\
\hline Servo-i & NA & NA & NA & NA & NA & NA & NA & NA & NA & NA & NA & NA \\
\hline PB840 & 0 & 1 & 1 & 0 & 1.7 & 1.8 & 0 & 0.7 & 0.7 & 1 & 1 & 1.3 \\
\hline $\mathrm{C} 3$ & 1.8 & 2.3 & NA & 2.3 & 3.2 & NA & 0.8 & 2 & NA & 1.5 & 2.3 & NA \\
\hline G5 & 0 & 2.2 & NA & 0 & 3.2 & NA & 0 & 1 & NA & 0.3 & 1.2 & NA \\
\hline CareStation & 0.3 & NA & NA & 0 & NA & NA & 0 & NA & NA & 1.2 & NA & NA \\
\hline V500 & 2.3 & 4.7 & NA & 0 & 5 & NA & 1.2 & 4.5 & NA & 2.8 & 7 & NA \\
\hline Avea & NA & NA & NA & NA & NA & NA & NA & NA & NA & NA & NA & NA \\
\hline V60 & 0 & 0.3 & 4.3 & 0 & 0 & 2 & 0 & 0.3 & 3.8 & 0.5 & 1.5 & 4.3 \\
\hline CMV mode & L1 & L2 & L3 & L1 & L2 & L3 & L1 & $\mathrm{L} 2$ & L3 & L1 & L2 & L3 \\
\hline Servo-i & NA & NA & NA & NA & NA & NA & NA & NA & NA & NA & NA & NA \\
\hline PB840 & 0 & 1 & 1 & 0 & 1.7 & 2 & 0 & 0.7 & 1 & 0.3 & 1 & 1 \\
\hline C3 & 1.8 & 2 & NA & 2.3 & 3 & NA & 1.3 & 1.7 & NA & 1.3 & 2 & NA \\
\hline G5 & 0 & 1.7 & NA & 0 & 2 & NA & 0 & 0.7 & NA & 0.5 & 1.2 & NA \\
\hline CareStation & 0 & NA & NA & 0.2 & NA & NA & 0.2 & NA & NA & 0.8 & NA & NA \\
\hline V500 & 2.3 & 4 & NA & 1.3 & 6.8 & NA & 1.7 & 3.8 & NA & 2.3 & 5 & NA \\
\hline Avea & NA & NA & NA & NA & NA & NA & NA & NA & NA & NA & NA & NA \\
\hline V60 & 0 & 0.7 & 4.7 & 0 & 0 & 2 & 0 & 0.2 & 3.2 & 0 & 0.8 & 4.7 \\
\hline \multicolumn{13}{|c|}{$\begin{array}{l}\text { Values are medians. The } \mathrm{L} 1, \mathrm{~L} 2 \text {, and } \mathrm{L} 3 \text { codes are explained in the text. } \\
\mathrm{L} 1 \text { include the values of } \mathrm{B} \rightarrow \mathrm{L} 1, \mathrm{~L} 2 \rightarrow \mathrm{L} 1 \text {, and } \mathrm{L} 3 \rightarrow \mathrm{L} 1 \text {. } \\
\mathrm{L} 2 \text { include the values of } \mathrm{B} \rightarrow \mathrm{L} 2, \mathrm{~L} 1 \rightarrow \mathrm{L} 2 \text {, and } \mathrm{L} 3 \rightarrow \mathrm{L} 2 \text {. } \\
\mathrm{L} 3 \text { include the values of } \mathrm{B} \rightarrow \mathrm{L} 3, \mathrm{~L} 1 \rightarrow \mathrm{L} 3 \text {, and } \mathrm{L} 2 \rightarrow \mathrm{L} 3 \text {. } \\
\text { NA = not applicable: did not synchronize }\end{array}$} \\
\hline
\end{tabular}

to all increasing and decreasing leaks in both PSV and CMV.

\section{Increasing Leak Versus Decreasing Leak}

Breaths to synchronization, miss-triggering, autotriggering and time to settle were higher for increasing than for decreasing leaks (Fig. 1, and see the supplementary materials at http://www.rcjournal.com). During increasing leak, auto-triggering occurred more frequently than miss-triggering, and during decreasing leak, misstriggering occurred more frequently than auto-triggering, in both NIV and invasive ventilation (see Fig. 1). As the magnitude of the change in leak increased, breaths to syn- 

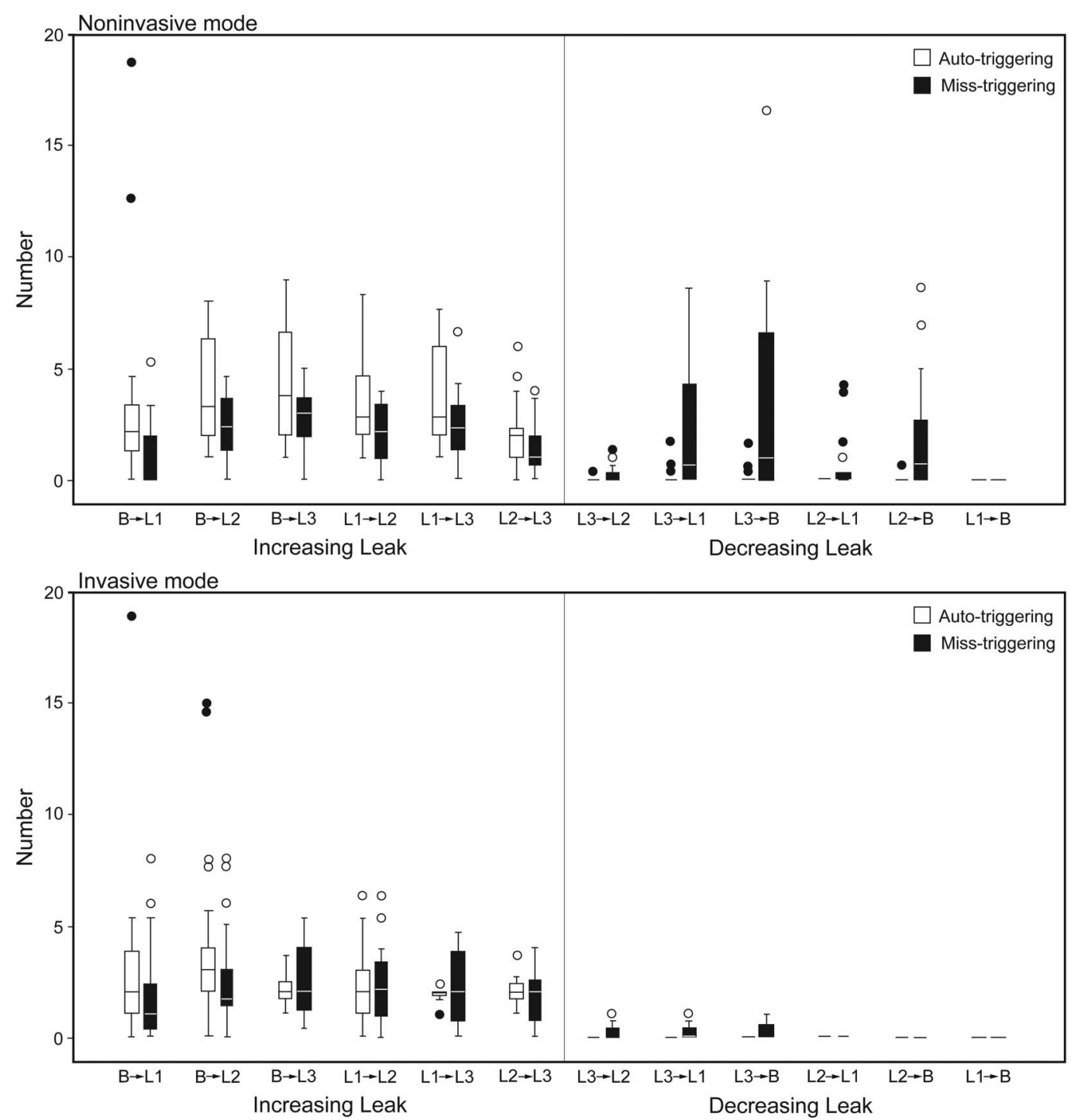

Fig. 1. Auto-triggering and miss-triggering under increasing and decreasing leak during invasive and noninvasive ventilation. The $B$ and $L$ codes are explained in the text. In the data bars the horizontal lines represent the median values, the tops and bottoms of the bars represents the IQR, and the whisker bars represent the maximum and minimum values except for outliers. The circles represent outliers $>1.5$ times the data-bar length. The dots represent outliers $>3.0$ times the data-bar length. In noninvasive mode, for miss-triggering, $P<.01$ for $\mathrm{B} \rightarrow \mathrm{L} 3>\mathrm{B} \rightarrow \mathrm{L} 1, P<.01$ for $\mathrm{B} \rightarrow \mathrm{L} 3>\mathrm{L} 2 \rightarrow \mathrm{L} 3, P<.001$ for $\mathrm{L} 3 \rightarrow \mathrm{L} 1>\mathrm{L} 1 \rightarrow \mathrm{B}, P<.001$ for $\mathrm{L} 3 \rightarrow \mathrm{B}>\mathrm{L} 1 \rightarrow \mathrm{B}, P<.01$ for $\mathrm{L} 2 \rightarrow \mathrm{B}>\mathrm{L} 1 \rightarrow \mathrm{B}, P=.002$ for $\mathrm{L} 3 \rightarrow \mathrm{B}>\mathrm{L} 3 \rightarrow \mathrm{L} 2$. There were no significant differences between the leak scenarios.

chronization and miss-triggering increased, but not autotriggering $(P<.001)$.

\section{COPD Versus ARDS Model}

In NIV mode, miss-triggering and time to settle were higher with the COPD model than with the ARDS model. Auto-triggering was higher in the ARDS model than in the COPD model (see the supplementary materials at http:// www.rcjournal.com).

In invasive mode, miss-triggering (PSV) and time to settle (PSV and CMV) were higher in the COPD model than in the ARDS model. Auto-triggering was higher in the ARDS model than in the COPD model in both PSV and CMV (see the supplementary materials at http://www. rcjournal.com).

\section{PEEP 5 Versus $10 \mathrm{~cm} \mathrm{H}_{2} \mathrm{O}$}

Breaths to synchronization, miss-triggering, autotriggering, and time to settle were higher with PEEP 10 than $5 \mathrm{~cm} \mathrm{H}_{2} \mathrm{O}$ in both NIV and invasive ventilation (see the supplementary materials at http://www.rcjournal.com). 


\section{A Comparison of Leak Compensation in Acute Care Ventilators}

\section{Comparison Among Ventilators}

We compared synchronization only among ventilators that could synchronize to all leak scenarios. In NIV the PB840 significantly outperformed the other 3 ventilators (Servo-i, C3, and V60) in 3 categories (breaths to synchronization, miss-triggering, and time to settle) (see the supplementary materials at http://www.rcjournal.com).

In invasive mode, the PB840 significantly outperformed the V60 in breaths to synchronization, miss-triggering, and time to settle in both PSV and CMV (see the supplementary materials at http://www.rcjournal.com).

\section{PSV Versus CMV}

There were significant differences in breaths to synchronization, miss-triggering, and time to settle between PSV and CMV, with CMV outperforming PSV in all 3 categories (see the supplementary materials at http:// www.rcjournal.com).

\section{Triggering Delay}

In NIV mode the time to baseline pressure was longer in the COPD model $(148 \pm 22 \mathrm{~ms})$ than in the ARDS model $(128 \pm 26 \mathrm{~ms})(P<.001)$ (Fig. 2). The time to baseline pressure was longer in the $\mathrm{C} 3$ and the V60 than in the Servo-i $(P<.001)$. All ventilators except for the G5 showed a time to baseline pressure $<150 \mathrm{~ms}$ at baseline leak. However, the $\mathrm{C} 3$ and the V60 showed time to baseline pressures over $150 \mathrm{~ms}$ in L2 and L3 (see Fig. 2).

In invasive mode the time to baseline pressure was longer in the COPD model $(139 \pm 25 \mathrm{~ms}$ and $139 \pm 23 \mathrm{~ms})$ than in the ARDS model (112 $\pm 15 \mathrm{~ms}$ and $113 \pm 15 \mathrm{~ms})$ in both PSV and CMV $(P<.001)$ (Fig. 3). There were no differences in mean triggering delay time between PSV and CMV in both the COPD model and the ARDS model (COPD model PSV vs CMV: $139 \mathrm{~ms}$ vs $139 \mathrm{~ms}, P=.89$ ) (ARDS model PSV vs CMV: $112 \mathrm{~ms}$ vs $113 \mathrm{~ms}, P=.23$ ). Comparing the PB840 and the V60, there was no significant difference between the 2 ventilators.

\section{Cycling Delay}

In NIV mode all the ventilators except for the G5 showed delayed cycling time within $50 \mathrm{~ms}$ in the COPD model. In the ARDS model all the ventilators except the $\mathrm{C} 3$ and the G5 showed a delivered inspiratory time $>100 \mathrm{~ms}$ shorter than the lung simulator inspiratory time in all leak scenarios (see Fig. 3). The C3 and the G5 showed prolonged cycling time in the ARDS model $(>2$ times the lung simulator inspiratory time) during L2 and L3. In CMV all the ventilators showed a cycling delay time of approximately 50-100 ms in both the COPD and the ARDS models (see the supplementary materials at http://www. rcjournal.com).

\section{Triggering Pressure and Tidal Volume}

Triggering pressure and delivered tidal volume are described in the supplementary materials at http://www. rcjournal.com.

\section{Discussion}

The main findings of this study are as follows:

- At baseline all the ventilators were able to synchronize without miss-triggering or auto-triggering, but there were wide variations in synchronization capability.

- The ventilators performed better during decreasing than increasing leak.

- The ventilators performed better with lower than with higher PEEP.

- Miss-triggering occurred more frequently and longer times were required to stabilize tidal volumes in the COPD model than in the ARDS model.

- Auto-triggering occurred more frequently in the ARDS model than in the COPD model.

- The ventilators were better able to avoid miss-triggering and achieve synchronization and stabilization of tidal volume in CMV than in PSV.

- The PB840 and the V60 were the only ventilators to maintain synchrony in all leak scenarios without adjustment of sensitivity or inspiratory termination criteria, but there were differences in performance between these 2 ventilators.

While previous studies have evaluated leak compensation in NIV alone, ${ }^{10,11}$ to the best of our knowledge this is the first assessment of leak compensation during invasive ventilation and NIV.

The ventilators performed better during decreasing than increasing leak scenarios. These findings were consistent with a previous report. ${ }^{14}$ As system leak increases, ventilators misinterpret the resulting changes in flow as inspiratory efforts, leading to frequent auto-triggering. If leak flow reaches the trigger threshold, auto-triggering occurs. Because of this, the frequency of auto-triggering does not depend on the magnitude of the increase in leak. ${ }^{6}$ On the other hand, if the leak is large enough, the ventilator may not detect respiratory efforts, leading to miss-triggering. Auto-triggering also may induce miss-triggering if inspiratory time is prolonged, due to auto-triggering overlapping the patient's next inspiratory effort. In other words, cycle asynchrony can produce trigger asynchrony. Thus, in or- 

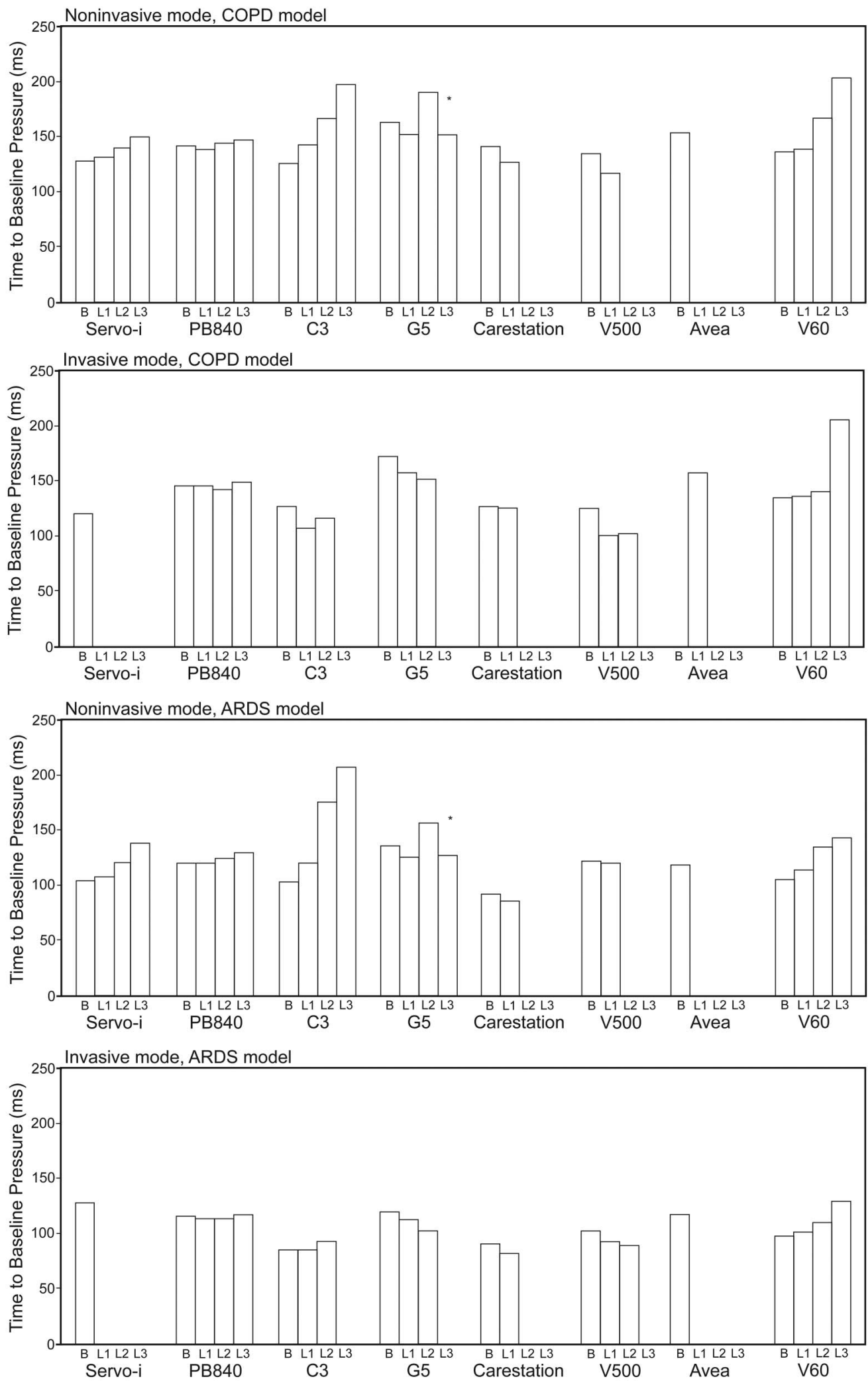

Fig. 2. Mean time to baseline pressure under leak scenarios in COPD and ARDS models. The $B$ and $L$ codes are explained in the text. All data include the PEEP values $5 \mathrm{~cm} \mathrm{H}_{2} \mathrm{O}$ and $10 \mathrm{~cm} \mathrm{H}_{2} \mathrm{O}$. Absence of a data bar indicates failure to synchronize during that leak scenario. * The data bars for the G5 ventilator show only PEEP of $5 \mathrm{~cm} \mathrm{H} \mathrm{H}_{2} \mathrm{O}$ in conditions L2 and L3 because the G5 did not synchronize at PEEP of $10 \mathrm{~cm} \mathrm{H}_{2} \mathrm{O}$ under conditions $\mathrm{L} 2$ and L3. 

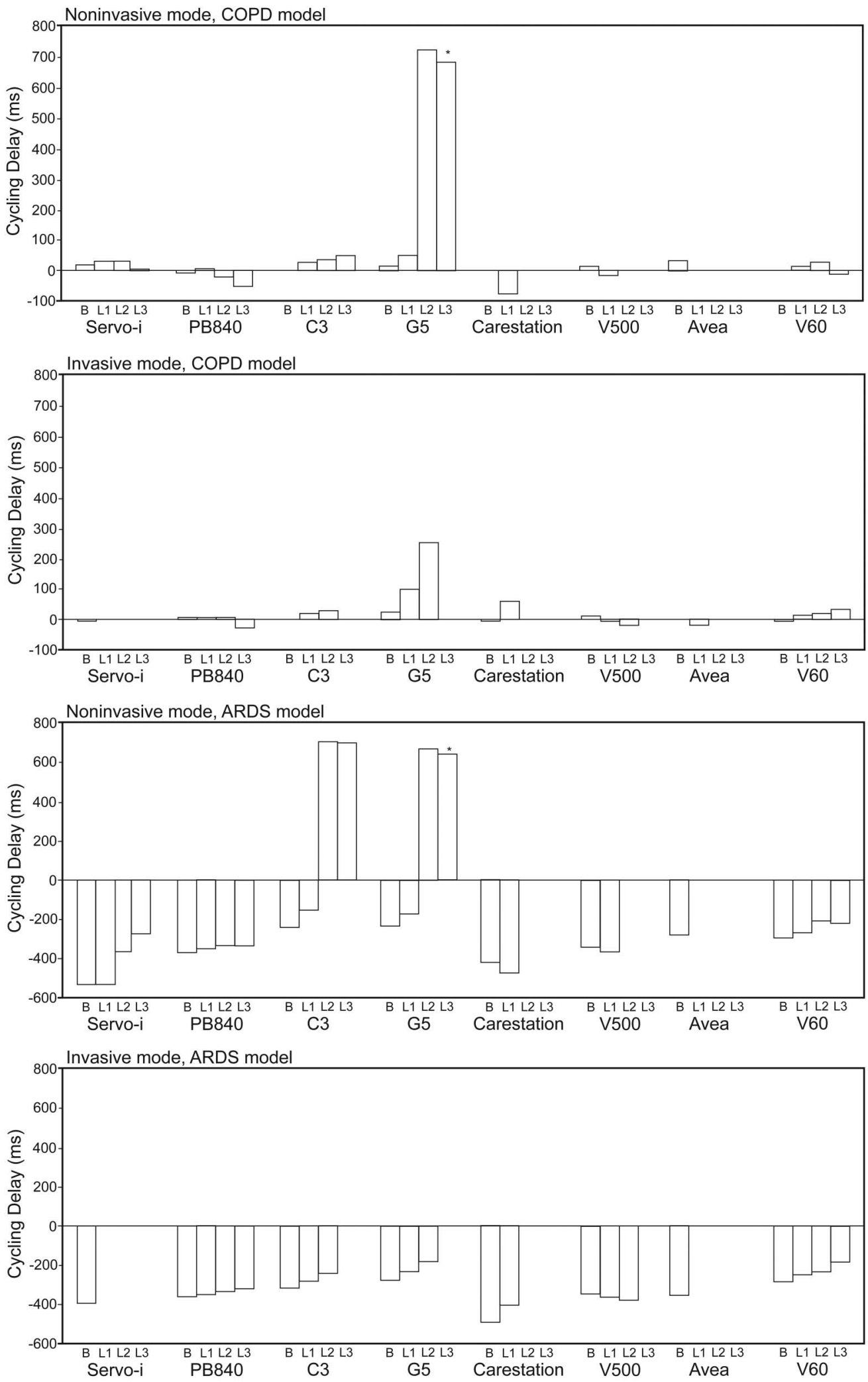

Fig. 3. Mean cycling delay time under leak scenarios in COPD and ARDS models. The $B$ and $L$ codes are explained in the text. Positive values represent delayed cycling and negative values represent premature cycling. All data include the PEEP values $5 \mathrm{~cm} \mathrm{H}_{2} \mathrm{O}$ and $10 \mathrm{~cm} \mathrm{H} \mathrm{H}_{2} \mathrm{O}$. Absence of a data bar indicates failure to synchronize during that leak scenario. * The data bars for the $\mathrm{G} 5$ ventilator show only PEEP of $5 \mathrm{~cm} \mathrm{H}_{2} \mathrm{O}$ in conditions L2 and L3 because the G5 did not synchronize at PEEP of $10 \mathrm{~cm} \mathrm{H}_{2} \mathrm{O}$ under conditions L2 and L3. 


\section{A Comparison of Leak Compensation in Acute Care Ventilators}

der for a ventilator to maintain synchrony in the presence of leak, the ventilator has to automatically adjust the trigger sensitivity and/or cycling time.

The ventilators may automatically decrease trigger sensitivity according to the level of leak to avoid autotriggering, but as the leak decreases the trigger sensitivity increases. This can lead to miss-triggering, particularly if the change is larger than the inspiratory effort. If the change in leak is smaller than the inspiratory effort, misstriggering is unlikely, though higher patient effort is required to reach this threshold. Because all the ventilators measure one or several cycles and adjust trigger/cycling for the subsequent cycles following a leak level change, it is not possible to synchronize on the exact breath that the leak changes. Due to this technical constraint, leak compensation on current acute care ventilators is limited in its ability to provide synchrony.

The ventilators performed better at PEEP $5 \mathrm{~cm} \mathrm{H}_{2} \mathrm{O}$ than at $10 \mathrm{~cm} \mathrm{H}_{2} \mathrm{O}$. Leak was created at the airway opening of the lung simulator, and the extent of the gas leak was nonlinearly related to pressure and flow. At higher PEEP the leak is increased due to the higher baseline pressure, and this may lead to an inability to distinguish the trigger signal from the leak.

In the COPD model miss-triggering was more frequent and required a longer time to stabilize tidal volumes than in the ARDS model. These results are consistent with those of previous reports. ${ }^{4,5}$ Compared to the ARDS model, the COPD model had increased time to baseline, triggering pressure, and delayed cycling time. This may be explained by the presence of higher airway resistance and lung compliance in the COPD model, which impede the transmission of respiratory effort to the ventilator and require larger efforts to reach the trigger threshold. On the other hand, auto-triggering was more frequent in the ARDS model than in the COPD model. Expiratory leaks can mimic an inspiratory effort, leading to auto-triggering. Premature cycling in the ARDS model prolongs expiratory time and may facilitate this expiratory leak effect. Another possible reason is that pressure signal noise induced by the low compliance of the simulated lung may also facilitate autotriggering. ${ }^{15}$ In the clinical setting, low respiratory drive, respiratory frequency, and absence of hyperinflation are associated with auto-triggering. ${ }^{16-18}$

In this study, all the ventilators except for the G5 showed acceptable cycling off capability (approximately $\pm 50 \mathrm{~ms}$ ), even in the presence of system leak in the COPD model. However, Ferreira et al reported that the Servo-i and the BiPAP Vision showed cycling delay times of approximately $200 \mathrm{~ms}$ and $800 \mathrm{~ms}$ respectively under similar lung mechanics and leak conditions. ${ }^{10}$ One possible reason is that we set the termination criteria to ensure that the end of inspiration of the lung model and the ventilator did not differ by more than $\pm 5 \%$ at baseline leak in the COPD model. In this study we set the cycling termination criteria at around $40-45 \%$ of peak inspiratory flow. In the ARDS model most of the ventilators showed premature cycling at $25 \%$ of peak inspiratory flow, due to the low compliance. In general, setting the expiratory trigger at a low percentage of the peak inspiratory flow may attenuate premature cycling. However, in the preliminary evaluation, all ventilators could not adjust the ending of inspiration to be within $\pm 5 \%$ of the lung model ending of inspiration at baseline leak, even when the termination criteria were set to the lowest possible values in the ARDS model; therefore we adjusted the expiratory trigger sensitivity to $25 \%$ of peak inspiratory flow. The $\mathrm{C} 3$ showed a prolonged inspiratory time $(>600 \mathrm{~ms})$ at L2 and L3 in the ARDS model (termination criteria was set at $25 \%$ of peak inspiratory flow) but not in the COPD model (the termination criteria was set at $45 \%$ of peak inspiratory flow). In these cases we believe that system leak may prevent air flow from reaching the preset expiratory flow, leading to a prolonged inspiratory time at lower values of peak inspiratory flow. Tokioka et al reported that delayed termination with a duty cycle of $>0.5$ sometimes occurred with the lowest values of termination criteria ( $1 \%$ of peak inspiratory flow) in 2 of 8 patients with ARDS or acute lung injury. ${ }^{9}$ In CMV, miss-triggering occurred less frequently and the ventilators required fewer breaths to synchronization than in PSV. As shown in the supplementary materials at http:// www.rcjournal.com, just after the system leak was increased, cycling delay due to inspiratory system leak induced miss-triggering, resulting in a longer time to synchronization during PSV. However, in CMV, inspiratory time was fixed and cycling delay did not induce misstriggering. This is one reason why CMV provided better synchronization than PSV. Calderini et al reported that in the presence of leaks, CMV provided better synchrony and patient comfort than PSV during NIV. ${ }^{19}$

According to our study, the leak compensation in acute care ventilators can correct partially or completely for system leak interferences, but there was wide variation among ventilators. Vignaux et al performed a bench study of 8 ICU ventilators featuring an NIV mode. ${ }^{20}$ For most of the tested ventilators, leaks led to an increase in trigger delay and a decrease in ability to reach the pressure target and delayed cycling. Similar to our findings, they found that NIV mode partially or completely corrected triggering and cycling delay, and there were marked variations between ventilators. Contrary to our study, some investigators have reported that dedicated NIV ventilators could produce better performance and synchronization than ICU ventilators in the presence of leak. ${ }^{7,8,21}$ Miyoshi et al evaluated the effects of gas leak on triggering function during NIV with dedicated NIV and ICU ventilators using a lung simulator. ${ }^{21}$ They found that the dedicated NIV ventilators triggered properly at several levels of leak (up to $44.2 \mathrm{~L} / \mathrm{min}$ 


\section{A Comparison of Leak Compensation in Acute Care Ventilators}

at $5 \mathrm{~cm} \mathrm{H}_{2} \mathrm{O}$ ) and triggering was more effective than with the ICU ventilators. However, the NIV mode was not tested in the ICU ventilators. Carteaux et al compared the operation of 8 ICU ventilators, 5 transport ventilators, and 6 NIV ventilators in NIV mode in a lung model and clinical study. ${ }^{11}$ In the lung model study they found that, even though there were wide variations in synchronization capabilities among ICU and transport ventilators, the Servo-i, PB840, and V500 could avoid auto-triggering completely when using NIV mode. In the clinical study they found that the NIV ventilators allowed better patient-ventilator synchrony than the ICU ventilators, but they did not test the Servo-i, PB840, or V500 in the clinical study. Ferreira et al evaluated the ability of 9 ICU ventilators and 1 NIV ventilator to function in the presence of leaks in a COPD model. ${ }^{10}$ As leak increased, all the ventilators except for the Servo-i and BiPAP Vision needed adjustments of triggering or cycling criteria to synchronize appropriately with the lung simulator. They concluded that the Vision had slightly better synchrony with triggering and the Servo-i with cycling. However, some ICU ventilators tested had not incorporated leak compensation. Since the manufacturers have not revealed the exact triggering and cycling algorithms used during system leak, it is difficult to explain the discrepancies among the different studies. However, considering the rapid growth of technology, it is critical to regularly repeat evaluations of ventilators to determine their ability to prevent triggering and cycling asynchrony caused by system leaks.

There were some limitations in this study. First, this study was not conducted on human subjects, raising the question of clinical relevance. However, lung simulator studies assure that the experimental conditions are the same for each ventilator evaluated. It is impossible to control the level of the leak or maintain stable baseline conditions in a clinical setting.

Another limitation is that we tested only a limited range of leaks and ventilator settings. However, we chose these to represent the range of leak flows that are likely to be encountered in clinical settings. In addition, we were interested in evaluating the maximum capabilities of the ventilators tested. Third, in some patients with acute respiratory failure, ventilatory efforts may be higher than that of our simulated respiratory efforts, and these higher efforts may affect our results.

\section{Conclusions}

All the ventilators synchronized at baseline leak, and some synchronized at low-level leak, but there were wide variations of ventilator performance. The PB840 and the V60 were the only ventilators to synchronize with simulated respiratory efforts in all leak scenarios both in NIV and invasive ventilation modes. Ventilator performance is strongly influenced by leak, lung mechanics, and PEEP setting. In clinical practice the ventilator is applied to patients with different lung mechanics, different ventilator settings, and rapid leak variations. Considering the above, the performance of a leak compensation algorithm is a crucial issue. Although it is unclear how different ventilators may affect clinical outcome, clinicians should be aware of these differences when applying leak compensation during invasive ventilation and NIV. Further studies are needed to determine the impact of different ventilators on outcome during NIV and invasive ventilation.

\section{REFERENCES}

1. Hess DR. Patient-ventilator interaction during noninvasive ventilation. Respir Care 2011;56(2):153-165.

2. Stauffer JL, Olson DE, Petty TL. Complications and consequences of endotracheal intubation and tracheotomy. A prospective study of 150 critically ill patients. Am J Med 1981;70(1):65-76.

3. Rashkin MC, Davis T. Acute complications of endotracheal intubation. Relationship to reintubation, route, urgency, and duration. Chest 1986;89(2):165-167.

4. Chao DC, Scheinborn DJ, Stearn-Hassenpflug M. Patient-trigger asynchrony in prolonged mechanical ventilation. Chest 1997;112(6): 1592-1599.

5. Thille AW, Rodriguez P, Cabello B, Lellouche F, Brochard L. Patient-ventilator asynchrony during assisted mechanical ventilation. Intensive Care Med 2006;32(10):1515-1522.

6. Vignaux L, Vargas F, Roeseler J, Tassaux D, Thille AW, Kossowsky MP, Brochard L, Jolliet P. Patient-ventilator asynchrony during noninvasive ventilation for acute respiratory failure: a multicenter study. Intensive Care Med 2009;35(5):840-846.

7. Vignaux L, Tassaux D, Carteaux G, Roeseler J, Piquilloud L, Brochard L, Jolliet P. Performance of noninvasive ventilation algorisms on ICU ventilators during pressure support: a clinical study. Intensive Care Med 2010;36(12):2053-2059.

8. Nava S, Bruschi C, Fracchia C, Braschi A, Rubini F. Patientventilator interaction and inspiratory effort during pressure support ventilation in patients with different pathologies. Eur Respir J 1997; 10(1):177-183.

9. Tokioka H, Tanaka T, Ishizu T, Fukushima T, Iwaki T, Nakamura Y, Kosogabe Y. The effect of breath termination criterion on breathing patterns and the work of breathing during pressure support ventilation. Anesth Analg 2001;92(1):161-165.

10. Ferreira JC, Chipman DW, Hill NS, Kacmarek RM. Bilevel vs ICU ventilators providing noninvasive ventilation: effect of system leaks: a COPD lung model comparison. Chest 2009;136(2):448-456.

11. Carteaux G, Lyazidi A, Cordoba-Izquierdo A, Vignaux L, Jolliet P, Thille AW, Richard JCM, Brochard L. Patient-ventilator asynchrony during noninvasive ventilation: a bench and clinical study Chest 2012;142(2):367-376.

12. IngMar Medical. ASL5000 Active Servo Lung Computerized Breathing Simulator and Ventilator Test Instrument user's manual. Pittsburgh: IngMar Medical; 2006.

13. Meyer TJ, Pressman MR, Benditt J, McCool FD, Millman RP, Natarajan R, Hill NS. Air leaking through the mouth during nocturnal nasal ventilation: effect on sleep quality. Sleep 1997;20(7):561-569.

14. Sulemanji D, Marches A, Kacmarek RM. Noninvasive ventilation, synchronization following increasing and decreasing leaks: a lung model study (abstract). Crit Care Med 2009;37(Suppl No. 12):A469.

15. Louis B, Leroux K, Isabey D, Fauroux B, Lofaso F. Effect of manufacturer-inserted mask leaks on ventilator performance. Eur Respir J 2010;35(3):627-636.

16. Imanaka H, Nishimura M, Takeuchi M, Kimball WR, Yahagi N, 


\section{A Comparison of Leak Compensation in Acute Care Ventilators}

Kumon K. Autotriggering caused by cardiogenic oscillation during flow-triggered mechanical ventilation. Crit Care Med 2000;28(2): 402-407.

17. Prinianakis G, Delmastro M, Carlucci A, Ceriana P, Nava S. Effect of varying the pressurization rate during noninvasive pressure support ventilation. Eur Respir J 2004;23(2):314-320.

18. Hill LL, Pearl RG. Flow triggering, pressure triggering, and autotriggering during mechanical ventilation. Crit Care Med 2000;28(2): 579-581.

19. Calderini E, Confalonieri M, Puccio PG, Francavilla N, Stella L,
Gregoretti C. Patient-ventilator asynchrony during noninvasive ventilation: the role of expiratory trigger. Intensive Care Med 1999; 25(7):662-667.

20. Vignaux L, Tassaux D, Jolliet P. Performance of noninvasive ventilation modes on ICU ventilators during pressure support: a bench model study. Intensive Care Med 2007;33(8):1444-1451.

21. Miyoshi E, Fujino Y, Uchiyama A, Mashimo T, Nishimura M. Effects of gas leak on triggering function, humidification, and inspiratory oxygen fraction during noninvasive positive pressure ventilation. Chest 2005;128(5):3691-3698.

This article is approved for Continuing Respiratory Care Education credit. For information and to obtain your CRCE

(free to AARC members) visit 